\title{
Intervenção estatal, centralização política e reforma burocrática: o significado dos departamentos administrativos no Estado Novo
}

Adriano Codato

\section{Introdução}

Este artigo trata da configuração político-burocrática do Estado brasileiro no período do Estado Novo (1937-1945).

Não pretendo, todavia, fazer uma história administrativa no sentido convencional do termo, já que procuro analisar a ossatura material do Estado a partir de um ângulo, senão incomum, infrequente. A literatura de sociologia política, história econômica, administração pública e história das instituições políticas brasileiras já havia inventariado e descrito a existência de inúmeros institutos, conselhos, departamentos e comissões para regular os vários setores da economia nacional no pós-trinta (CUNHA, 1963; IANNI, 1971; DinIz, 1991). Interessa-me mostrar, ao invés, a aparelhagem política que permitiu que o governo federal regulasse as relações de poder com as classes dirigentes estaduais.

Para tanto, investigo a origem e os modos de funcionamento do sistema estatal autoritário após a edição do Decreto-lei no 1202, em 8 de abril de 1939. Descrevo o 
processo de criação dos departamentos administrativos dos estados, analiso sua posição estratégica no quadro institucional do Estado Novo e especulo sobre o significado, para o regime, de uma agência com as características e as atribuições dos chamados "daspinhos". A hipótese é que o Código Administrativo (ou Código dos interventores), conforme ficou conhecido o Decretolei no 1202/39, é estratégico para entender o lado propriamente político do processo e do projeto de construção de um Estado "forte, autônomo e soberano", como se convencionou dizer nos anos 1930, no Brasil. Esse código permite, igualmente, não apenas redesenhar os organogramas do governo ditatorial, mas indicar as formas de recrutamento dos grupos dirigentes estaduais e o locus institucional onde se dá e de onde advém esse mecanismo, ressaltando o papel determinante, embora nem sempre muito visível, das instituições burocráticas do Estado Novo.

O Estado Novo, e mesmo o primeiro governo de Vargas, foi percebido e descrito normalmente como um regime personalista, isto é, como sistema ordenado e garantido apenas pelo carisma do líder, conforme o roteiro do "populismo" (SoLA, 1990); ou como sistema apoiado exclusivamente nas relações tradicionais de confiança-baseadas no clientelismo -, que ligavam as oligarquias regionais ao poder central, exatamente como ocorria durante a Primeira República (MARTins, 1983). Ao contrário, insisto aqui no papel central das instituições de governo para compreender o funcionamento concreto desse regime político.

\section{O problema da autonomia do Estado brasileiro pós-oligárquico}

O exame da estrutura institucional do Estado brasileiro no pós-1930, e do arranjo político-ditatorial no pós-1937, não pode limitar-se à definição das funções gerais desse Estado - a promoção do desenvolvimento capitalista -, à caracterização da sua ideologia (autoritária), ou à análise dos processos históricos que tornaram possível a modernização conservadora. Além do mais, há, por parte da literatura especializada, certa insistência em entender as transformações do aparelho do Estado tão somente em função do processo de industrialização e das novas formas de negociação com as classes economicamente dominantes, desprezando-se, com isso, tanto o jogo político intraelites quanto o marco institucional que regulou e viabilizou essas disputas.

De maneira geral, todos os autores que estudaram o período concordam, sem, contudo, avançar muito além desse ponto, que o caráter centralizado e monolítico do Estado brasileiro durante esse período de sua história política autorizou o alto grau de autonomia que ele desfrutou em relação à sociedade (DINIZ, 1991, p. 79). Ainda que isso seja correto, resta uma série de questões a serem investigadas. Por exemplo: se a diminuição da heteronomia do Estado é um efeito da concentração do poder político no governo central, a concentração resulta do que exatamente? Quais os seus mecanismos? Quais os seus aparelhos? Como eles estavam dispostos e hierarquizados? Quais as relações de poder entre eles e as elites que os comandava?

Fausto (1972) ponderou, já há um bom tempo, que a constatação de que durante o regime de 1937 o Estado tornou-se o polo dominante diante da sociedade, é lugar comum. Seria recomendável superar essa declaração incontestável e excessivamente genérica em nome de uma explicação efetiva sobre como isso se deu. Assim, "o que importa saber - e para isso nos faltam estudos - é como se efetivou 
concretamente esta dominância, precisando-se o grau de autonomia do Estado diante das diferentes pressões articuladas pela sociedade" (FAusto, 1972, p. 85). Na mesma linha, Souza advertiu que "A quase totalidade dos estudos existentes sobre o Estado Novo prescinde de uma análise mais detida da estrutura de poder que então se constituía, e dos mecanismos que lhe davam feição marcadamente burocrática" (SouzA, 1990, p. 84).

Talvez não faltem mais estudos históricos descritivos sobre esse tema atualmente. Essas advertências, todavia, são mais complicadas, porque elas não se referem à quantidade de informações acumuladas pelos investigadores. Elas, na realidade, põem em questão quatro problemas interligados, mas distintos, e que não são tão evidentes quanto a relação desbalanceada entre o Estado e a sociedade faz acreditar. Esses problemas são, do meu ponto de vista, os seguintes: $\imath$ ) as condições sócio-históricas da autonomia do Estado brasileiro; ii) os mecanismos políticoinstitucionais que produzem e/ou permitem essa autonomia; $\ddot{i i}$ ) a intensidade sociopolítica dessa autonomia; $i v$ ) os agentes políticos (ou burocráticos) que desfrutam dessa autonomia; e $v$ ) os agentes sociais, diante dos quais se exerce essa autonomia.

Neste artigo trato apenas de um item desse rol de problemas: os mecanismos que produzem e garantem a independência política do governo federal. Na sequência, discuto a configuração do Estado ditatorial, focalizando três aspectos da sua história político-administrativa: a criação dos departamentos administrativos dos estados, a posição dos departamentos administrativos no organograma e a significação dos departamentos para a estrutura política do regime. Eles são uma chave, entre tantas outras possíveis, para entender como foi possível desmontar não só os esquemas oligárquicos tradicionais de negociação e solução de conflitos intraelite, mas aniquilar seus recursos institucionais - em especial, partidos e parlamentos.

Antecedentes políticos e burocráticos dos departamentos administrativos

Carone (1977) tem razão em lembrar que, do ponto de vista político-adminis-

“O Estado Novo, e mesmo o primeiro governo de Vargas, foi percebido $e$ descrito normalmente como um regime personalista, isto é, como sistema

ordenado $e$ garantido apenas pelo carisma do líder, conforme o roteiro do “populismo."

trativo, a consolidação do regime ditatorial do Estado Novo é lenta e insegura, se fazendo segundo as circunstâncias, pois falta ao governo uma orientação única, ideológica e política, pelo menos no que diz respeito ao período logo após o golpe de Estado, em novembro de 1937. A melhor evidência do caráter processual da institucionalização política do governo 
autoritário, das dificuldades da centralização do poder, e da demora na regulamentação legal das relações entre as oligarquias estaduais e a União é o fato de que, entre a extinção dos partidos e associações políticas (em dezembro de 1937) e a edição do Código dos interventores (em abril de 1939), vai quase ano e meio (CArone, 1977, p. 267). Ademais, certa inércia - resultado das acomodações necessárias entre grupos vitoriosos e facções derrotadas -, além das lutas pelo domínio da situação política nos estados, que decorrem desse imobilismo que se segue ao golpe, adia a fixação de medidas definitivas de configuração administrativo-política do regime. Contudo, diz ele, "com o correr do tempo, a indeterminação administrativa pesa negativamente", o que obriga o governo a formular o decreto que, enfim, subordina completamente estados e municípios ao poder central (CARONE, 1982, p. 155).

É preciso notar que esse decreto - o Decreto-lei $\mathrm{n}^{\circ} 1202$ dispunha sobre a concepção, provimento e funções dos departamentos administrativos - não previa uma inovação institucional no sistema político brasileiro tão original, assim como Loewenstein registrou (1944). Em certos aspectos, os departamentos administrativos revivem os antigos conselhos consultivos de Estado $^{1}$, e a ideia de recriá-los, em abril de 1939, corresponde menos a um expediente improvisado diante das pressões dos grupos oligárquicos que haviam ficado de fora dos esquemas políticos arrumados às pressas nas interventorias comandadas pelos tenentes (como no arranjo de 1931), e mais à pretensão do Estado autoritário de reorganizar todo o processo de governo, e a distribuição de poder dele resultante, em novos moldes. Nesse sentido, o texto legal de 1939 pode ser lido como indício de duas limitações do sistema de interventorias federais: i) faltava regulamentar a intervenção decretada pelo art. 176, parágrafo único da Constituição de 1937, organizando burocraticamente a administração política de estados e municípios (assunto diferente, bem entendido, da racionalização dos serviços públicos, que não se confunde com a primeira); e ii) faltava criar um instrumento politicamente capaz de garantir e aprofundar a centralização do poder decisório, levando adiante a obediência estrita dos estados aos objetivos do regime, propósito que somente a confiança pessoal do ditador no interventor seria incapaz de providenciar.

Carone é excessivamente otimista ao ver no Código dos interventores, de agosto de 1931 (como depois alguns analistas viram no Código Administrativo de abril de 1939), um dos exemplos mais conscientes da história da reforma administrativa brasileira. Ele teria representado a tentativa dos vitoriosos da Revolução de 1930 de substituir a política partidária pela técnica administrativa. O Decreto nº 20348 seria, nesse sentido, um passo importante dentro de uma política de moralização pública. O tema será reprisado, em parte, durante o Estado Novo, com o Dasp. O próprio Carone reconhece que o documento de 1931 deveria enquadrar os tenentes, diminuir os "abusos" por eles praticados durante essa primeira fase do Governo Provisório e, de quebra, contornar "as restrições das máquinas administrativas locais contra eles" (CARONE, 1978, p. 441 e p. 28, respectivamente). Como o código original proibia os estados de contrair empréstimos sem a prévia autorização do governo federal e restringia os recursos que cada estado poderia destinar às suas forças policiais - impedindo-as de rivalizar com o Exército nacional -, acabou se tornando, na prática, muito mais medida e 
instrumento de centralização do poder na esfera federal do que qualquer coisa. É esse aspecto, ainda que não por meio dos mesmos dispositivos, que conecta o Decreto de 1931 ao Decreto de 1939.

\section{A gênese institucional do Decreto-lei ${ }^{\circ} 1202$}

Se a fórmula autoritária de governo, imposta pelo golpe de novembro e legalizada pela Constituição, pretendia resolver certos problemas colocados pelos círculos dirigentes do regime - como, por exemplo, o poder residual das oligarquias -, ela não foi tão eficiente para construir, como foi para destruir. Duas questões que estão na base da edição do Decreto-lei no 1202 - a questão da administração pública e a questão, tão ou mais complicada, da representação política dos estados permitem pôr em evidência o problema da gênese institucional da estrutura ditatorial e, em menor medida, o tema da autonomia e da capacidade do Estado autoritário.

O caráter ultracentralizado e, principalmente, secreto do processo decisório sob o Estado Novo, o formalismo de todos os comentários constitucionais (PONTES DE Miranda, 1938) e o sentido triunfante das explicações oficiais tornam problemático refazer o percurso de qualquer decisão do regime autoritário, desde sua formulação até sua implementação. Notas na imprensa sobre questões políticas são escassas ou protocolares e apenas registram, burocraticamente, feitos e fatos do governo. $\mathrm{O}$ caso da concepção de um departamento administrativo em cada estado dos Estados Unidos do Brasil não é diferente. É mais fácil ler sua história a partir dos conflitos reais, que exigem um aparelho com as características e os poderes referidos no Decreto-lei no 1202, do que a partir de um pretenso plano de reforma da administração pública.

Como não há, na documentação disponível, um projeto por escrito, uma minuta ou uma exposição de motivos que anteceda e fundamente o decreto presidencial, tentarei reconstruir sua gênese institucional a partir da história política da organização, a fim de inseri-lo na configuração institucional do Estado ditatorial.

A prática do regime de redesenhar frequentemente o marco institucional, ou introduzir modificações marginais no sistema decisório, poderia sugerir mais ajustes graduais - seja em função de defeitos detectados no arranjo inicial do sistema estatal, seja em função das adaptações a um meio ambiente hostil - do que uma ação cega de tentativa e erro. Em todo caso, na ausência de uma ruptura institucional efetiva - uma transformação institucional radical -, a ideia de Krasner (1984) da vigência de um sistema institucional equilibrado, pontuado por momentos de crise, é mais descritiva do que realmente ocorre nesse caso.

Algumas evidências esparsas sugerem quatro razões diferentes, de peso desigual, que estão na origem dos departamentos. Em primeiro plano, há a necessidade de melhor repartição de funções entre governos estaduais e governo federal, em termos orçamentários. O principal seria saber quem financiaria o quê, quando, como e com que recursos; daí o papel atribuído à agência na revisão do planejamento anual de receitas e gastos elaborado pela Secretaria de Governo da Interventoria. Possivelmente, esse foi o motivo inicial do Código Administrativo. Menos de um ano após a vigência da Constituição de 1937, Vargas anotou, contrariado, os problemas decorrentes do desencontro de contas entre os estados e a União, os aborrecimentos 
que a irresponsabilidade fiscal dos primeiros causava e como, dadas as circunstâncias políticas, isso havia se tornado inadmissível, uma vez que os políticos não tinham mais como barganhar vantagens e recursos, como de hábito:

É curioso como os estados procuram por todos os meios arrancar dinheiro à União. No regime constitucional, em que o governo federal só se mantinha a custa da transigência com os mandões locais, este sistema era corrente. Hoje, porém, as coisas estão diferentes. É preciso que os estados façam administração dentro dos próprios recursos, e não com o dinheiro do Banco do Brasil. A União realiza nos estados o que está no programa federal (VARgAs, vol. II, p. $160-161)^{2}$.

Retomando e refazendo a questão: como e por que as instituições políticas desse Estado específico mudaram ao longo do tempo? Trata-se de uma necessidade administrativa, sem dúvida, mas cuja solução, política, deveria ser imposta conforme as regras burocráticas do novo regime. Ou seja, mais um aparelho, entre o presidente e os interventores, para supervisionar o processo decisório dos estados. Em segundo lugar, e em segundo plano, estava a exigência, decorrente da primeira, de controlar burocraticamente mais e melhor as situações estaduais - i.e., as oligarquias locais - e, em especial, o próprio interventor, nomeado pelo presidente.

Essa evidência pode ser lida tanto nas pretensões explicitadas pelo presidente de eliminar as práticas e os vícios decorrentes da antiga política dos governadores - em especial, as barganhas -, quanto nas reações que a implementação dos dispositivos, previstos no Decreto-lei no 1.202 , suscitou na classe política. Almir de Andrade, ao comentar a excelência da lei orgânica dos estados (o nome pomposo desse decretolei), lembrou que os poderes conferidos aos interventores são muito mais limitados do que o dos antigos governadores de estado. Para que se tenha uma ideia precisa disso, ele enfatiza que o artigo 32 previa nada menos de vinte e três hipóteses, em que a validez dos decretos-leis expedidos pelos interventores depende estritamente da aprovação do presidente da República. Além disso, "os artigos 33 e 24 da lei orgânica estabelecem quinze hipóteses diferentes, nas quais é vedado aos estados e municípios expedir decretos ou praticar atos $[. .$.$] que [. .$.$] digam respeito a matérias$ reconhecidas pela União como de sua exclusiva competência" (ANDRADE, 1941 apud Rodriguez, 1983, p. 157-159).

Do momento em que o Código dos Interventores começou a ser tratado em despachos com o ministro da Justiça, em 16 de janeiro de 1939, à sua publicação no Diário Oficial, em 10 de abril, os prepostos estaduais ficaram três meses em estado de alerta, aguardando o que viria pela frente. Imediatamente depois de divulgado o decreto, tornaram-se "um pouco apreensivos" (a impressão é de Getúlio Vargas) e, no mês seguinte, atacaram abertamente a nova legislação.

Benedito Valadares era um dos que demonstraram, segundo o presidente, "má vontade" com o código administrativo. E é bem possível que ele previsse grande oportunidade para os mandachuvas da política mineira se rearticularem e se voltarem contra seu governo; ou que fosse isso e mais uma vingança pessoal de Francisco Campos - grande arquiteto do negócio todo - contra sua nomeação para o Governo de Minas. Acertou-se então que, após suas gestões contra o decreto-lei, e 
não sendo possível voltar atrás depois de divulgada a decisão no Diário Oficial, "seriam feitas algumas retificações por ele sugeridas"; uma vez "publicadas estas, seria o Código posto em execução”. Cordeiro de Farias, por seu turno, interventor do Rio Grande, simplesmente ameaçou renunciar "se não fossem atendidas suas ponderações" - sendo a mais importante a de que os departamentos administrativos fossem tão somente órgãos consultivos, não deliberativos. Não foi atendido e também não renunciou. Em junho, o Decreto-lei no 1202 foi revisto. Mesmo assim, o presidente da República enfrentou mais um pedido de exoneração, o de Osvaldo Aranha, que, entre motivos alegados e não alegados, engrossou o coro de oposição à lei orgânica dos estados ${ }^{3}$. Vargas anota que, em meio a esse vai e vem do chanceler, Maciel Filho procurou repercutir as críticas do ministro do Exterior em seu jornal, O imparcial. Essa história merece ser contada.

Em correspondência particular ao presidente, à mesma época, o jornalista voltou a expor sua divergência total com Francisco Campos, ministro da Justiça e autor declarado do novo sistema de governo. Por meio de uma argumentação complicada, de umas tantas referências a conspirações, antipatias pessoais e mexericos palacianos envolvendo personagens centrais e periféricos da política mineira, Maciel sustentava basicamente que a gang (sic) que atuava sob a direção do ministro da Justiça e Negócios Interiores, por meio da recém-criada Comissão Revisora de Leis e Decretos ${ }^{4}$ (Sabóia de Medeiros, Pedro Batista Martins, Otacílio Negrão e Múcio [ilegível]), tinha adquirido o poder de, arbitrariamente, explorar os decretos-leis em proveito próprio. Isso conduzia, segundo o informe do jornalista, a um clima de incerteza jurídica que afetava a atividade comercial, a industrial e o direito de propriedade. Ele profetizou que, enquanto for possível fazer decretos com forma de leis gerais para resolver casos particulares, não haverá ambiente adequado para investimentos. A lei orgânica seria, então, um dos capítulos centrais dessa atividade legiferante e casuística, elaborada por advogados perigosos. Na parte do bilhete manuscrito de Maciel Filho a Vargas,

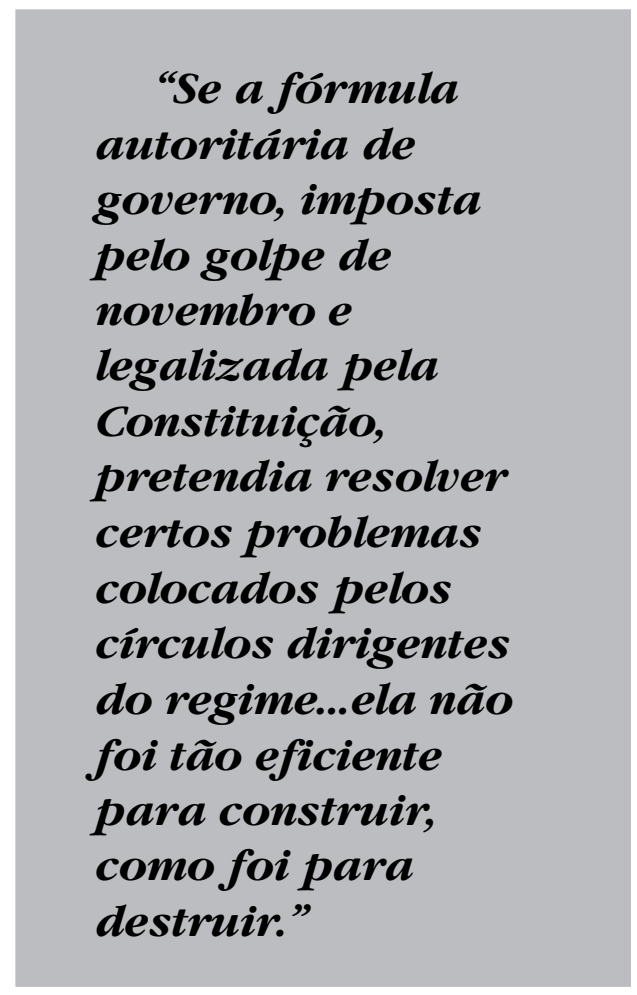

em que enumera suas divergências técnicas em relação ao decreto dos interventores, pode-se ler uma lista de defeitos de ordem jurídica: $\imath$ ) "O texto do decreto fere, em mais de 15 artigos, a Constituição de 10 de Novembro" (embora não os especifique); ii) "nossas instituições de direito público não admitem a subordinação dos governos dos estados - ainda que interventores - aos 
ministros, que são secretários do presidente"; e iii) "para se determinar a orientação administrativa dos interventores, não é necessário um decreto; basta uma circular de administração ordinária e mais dois ou três funcionários na Secretaria da Presidência para a correspondência, arquivo" etc. Politicamente, o Código Administrativo, adotado em um momento em que o "governo federal não [estava] uniforme, constituindo um só bloco, [i.e., sem grandes conflitos] nem forte financeiramente, nem organizado tecnicamente para uma ação dessa envergadura" ${ }^{5}$, a ação de criar esses departamentos arriscava, segundo o autonomeado consultor do presidente, em duas frentes: ao concentrar todos os poderes no Rio de Janeiro, isto é, na União, unificava os estados contra o presidente (não se entrega a adversários uma bandeira tão popular como o federalismo") e facilitava, sabe-se lá como, a execução de um golpe técnico contra o próprio Vargas, possivelmente por meio de alguma desculpa jurídica ${ }^{6}$.

Não só pelo comentário legal de Almir de Andrade, mas pelas reações aqui referidas, pode-se especular que um dos propósitos enfiados na legislação, a princípio destinada apenas a ordenar as finanças públicas, pretendia diminuir significativamente a autonomia dos interventores e aumentar, na mesma proporção, o poder fiscalizador do ministro da Justiça. No inspirado discurso que pronunciou na abertura da Conferência Nacional de Economia e Administração, em 10 de novembro de 1939, Vargas pontificou sobre os avanços na esfera administrativa, após dois anos exatos do Estado Novo, e celebrou sua lei orgânica dos estados, a providência mais importante do governo para eliminação dos resquícios do regionalismo ou caudilhismo. Essa medida derrubava os obstáculos políticos ao progresso nacional, entre eles "a política facciosa, em que as dedicações eleitorais eram pagas com favores onerosos; o provincialismo, que criava e multiplicava obstáculos ao livre curso dos valores econômicos; os particularismos, que estabeleciam preferências para a outorga de benefícios; a pretensão de hegemonias, que prejudicavam o entendimento de todos os brasileiros" (VARGas, 1940, p. 74 e 124).

Pode-se especular, com razoável margem de certeza, que a criação dos departamentos administrativos responde a uma necessidade política - bem mais complexa do que o controle e a supervisão burocrática das finanças do interventor -, cuja solução, também política, deveria ser imposta conforme os objetivos declarados de centralização do novo regime.

Uma prova adicional das contradições, em que estava enredado todo o sistema de interventorias de 1938 em diante, e que repercutiam seja sobre a relação entre a Presidência e os estados - o que eu chamarei de conflito interelite -, seja sobre a política interna de cada estado - conflito intraelite-, deriva do descontentamento ou do desconforto que sua baixa eficiência suscitava em personagens situados nas mais diversas posições.

Segundo Francisco Campos, essa revolução jurídica, que seu gênio político promoveu, não era só justificável. Ela estava plenamente de acordo com os princípios expostos na Carta de 1937, que exigiam todo poder ao presidente. Os departamentos administrativos deveriam, segundo o ministro, apenas preencher o vazio institucional que o constituinte não previu (e que também não reconhecia como um defeito de sua autoria), a fim de complementar a ação da Interventoria, introduzindo mais uma coluna no edifício. A nova medida, 
concretizada no Decreto-lei no 1202, "não procurava efetuar a centralização administrativa"; essa era um pressuposto de todo o sistema constitucional. Ela "visa, apenas, a centralização política” (CAMPOS, 1940, p. 170-171). Campos apresenta, assim, os departamentos como um progresso político, não como resultado natural da evolução do sistema institucional, mas com uma peculiaridade: os dois aparelhos Departamento e Interventoria - e seus ocupantes eventuais deveriam assumir, antes de tudo, um compromisso ideológico com o Estado Novo, ou seja, acatar como seus "os propósitos de defesa e de consolidação do regime" do presidente Vargas (CAmpos, 1940, p. 115).

Os departamentos administrativos respondem a uma necessidade ideológica do regime - bem mais sutil do que o controle político dos oligarcas -, cuja solução, institucional, deveria ser imposta conforme os preceitos doutrinários do seu jurista.

Esse espaço vazio na estrutura governamental foi identificado também pelas oligarquias não incluídas no novo esquema. Se a antiga fórmula autoritária da centralização (presidente + interventor), adaptada do Governo Provisório, pretendia achar a solução para os problemas práticos da governança, ao simplesmente enquadrar as situações estaduais, acabava criando outros, tão ou mais delicados. Ao contrário do que poderia parecer, a destruição dos canais tradicionais de agregação e representação de interesses - partidos, parlamentos - não reduzia o pluralismo no universo das elites, mas promovia-o, já que havia vários critérios de escolha do representante estadual, o que poderia aumentar o conflito interelites. Por outro lado, esse "pluralismo limitado”, para falar como Linz (1980), não era ainda amplo o suficiente para expressar, politicamente, as demandas por participação dos grupos oligárquicos excluídos, marginalizados ou integrados de forma precária ao sistema político ditatorial. Essa imprevidência acrescentava ao regime outra dificuldade: agravava o conflito intraelite.

A indignação dos políticos do Paraná, diante das atitudes e do comportamento do interventor nomeado por Vargas, é prova disso e dá o tom da carta-protesto que enviaram ao presidente da República em 1 de fevereiro de 1938, dando-lhe ciência do divórcio entre a opinião pública paranaense (isto é, eles mesmos) e a pessoa do Sr. Manoel Ribas. O rosário de reclamações ia do peso dos impostos ao temperamento impulsivo, intratável, afrontoso e agreste do interventor; dos seus esquemas para beneficiar-se pessoalmente das rendas dos jogos de azar à sua falta de cultura e modos; do superfaturamento de obras à dependência de conselhos políticos de terceiros etc. A sugestão era que ele fosse substituído imediatamente 7 . Em São Paulo, a situação não era melhor. Vargas registrou que seu pedido, para que o PRP fizesse, logo após o golpe de 1937, um governo de concentração com Cardoso de Melo Neto (do PC), não seria atendido pelos mesmos motivos que opunham os políticos paranaenses ao seu próprio interventor: "desprestígio, negociatas e dificuldades de sindicância para apurar responsabilidades" (VARGAs, 1995, vol. II, p. 91 e 93; entradas dos dias 9 e 14 dez. 1937). Em 1939, provavelmente muito preocupado com a qualidade da administração pública, o PRP rompeu politicamente com Ademar. No ano seguinte, abriu campanha pública contra a administração calamitosa do Sr. Ademar de Barros, para repetir o título de um livro famoso à época, e em 1941 conseguiu enfim sua destituição. Segundo Hayashi, a causa das denúncias de corrupção contra o interventor teriam 
sido os interesses políticos de elementos perrepistas que se consideravam marginalizados do poder. Ademar, segundo consta, "demitira todos os prefeitos do estado e, para substituí-los, nomeara elementos jovens, alguns sem qualquer ligação com o PRP e outros vinculados a grupos rivais do partido" (HAYAshi, 1996, p. 122). A ironia, contida na queixa do doutor Armando de Sales Oliveira ao general Góes Monteiro, de que "as reformas com o colorido característico do novo Estado, prometidas para revelar a felicidade aos brasileiros, foram adiadas, e não se falou mais nos órgãos que deveriam substituir a representação nacional destruída" não foi completamente em vão (OLIVEIRA, 2002, p. 460$).{ }^{8}$ Com a instituição do Departamento Administrativo, cumpria-se enfim, e dessa forma, a promessa, contida na Carta de 10 de Novembro, de encontrar uma solução diferente, mais moderna e mais eficiente, para o problema da representação política.

O Departamento Administrativo responde a uma necessidade social (bem mais útil do que a mera doutrinação ideológica da elite estadual), cuja solução, pragmática, deveria ser imposta conforme os procedimentos usuais da época: a inclusão de alguns nomes a mais na administração ordinária do aparelho do Estado. Nesse sentido, em vez de seguir a lógica do clientelismo, o aparelho é um sucedâneo dos conselhos econômicos corporativos trata-se de um corporativismo político.

O Departamento Administrativo não foi criado para isso, ou em função das necessidades referidas por um ator poderoso e onisciente. Sustento que ele serviu para isso, o que é bem diferente. $\mathrm{Na}$ explicação da sua gênese, é preciso ter presente tanto o contexto quanto o timing do processo político nacional, isto é, a sequência de acontecimentos. Instituída a Constituição em novembro de 1937, ao longo do tempo tornou-se cada vez mais necessário, e depois cada vez mais urgente, criar alguma instituição representativa que pudesse, sem desorganizar muito o esquema então planejado, articular e agregar interesses políticos, acomodando a complexidade das situações regionais, divididas e subdivididas em grupos submetidos exclusivamente ao reduzido jogo dos interventores. A instituição dos departamentos administrativos dos estados, em abril de 1939, parece expressar não esse desígnio, mas a percepção do problema. $\mathrm{Na}$ realidade, esse deve ter sido o ganho adicional e inesperado da intenção presidencial de organizar melhor a intervenção federal. A função fiscalizadora - política e administrativa - atribuída ao aparelho sugeria a preocupação de Vargas em dotar o sistema político de um mecanismo de contrapeso ao poder dos interventores, em que o próprio presidente surgisse como árbitro final das disputas intrarregionais. Essa versão da história fica mais visível quando se olha para a ordem políticoburocrática do regime.

\section{O lugar do Departamento no organograma de governo}

A posição formal do Departamento, no sistema administrativo do Estado Novo, permite deduzir as relações estratégicas entre os diversos centros de poder, do nível federal ao municipal, e suas respectivas funções político-burocráticas.

Mesmo um exame superficial do organograma - referido apenas às competências respectivas desses aparelhos, tal como definidas administrativamente na legislação - sugere alguns tópicos interessantes. Destaco, sem me aprofundar muito, 
alguns aspectos políticos que essa configuração institucional indica.

Essa estrutura, embora possa ser separada analiticamente em quatro compar- e adaptada sucessivamente para operar como uma máquina de concentração e centralização de poder e decisões e funcionou, de 1939 a 1945, até onde se pôde

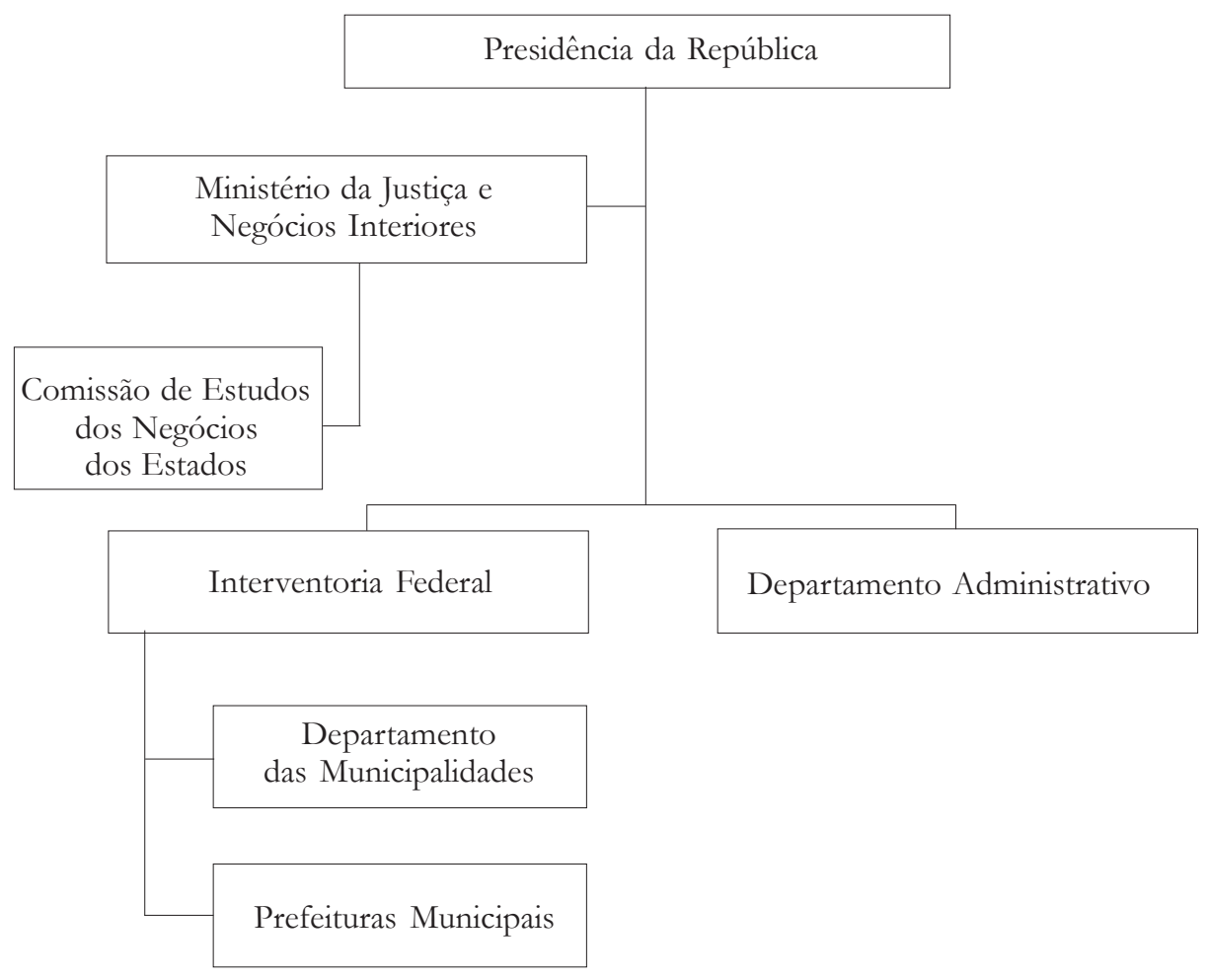

Fonte: o autor, a partir do Decreto-lei 1 202/39.

Organograma 1: Organização política da administração pública no regime da Constituição de 1937

timentos ou em quatro níveis de autoridade, níveis esses que recobrem e se confundem com a "divisão administrativa" do regime - no primeiro nível, a Presidência da República, a última instância do sistema estatal; no segundo nível, o Ministério da Justiça e Negócios Interiores e a Comissão de Estudos dos Negócios dos Estados; no terceiro nível, a Interventoria Federal e o Departamento Administrativo; e no quarto nível o Departamento das Municipalidades e as prefeituras -, foi construída, redefinida estimar, de forma coordenada. A ordenação desse sistema, a posição de cada aparelho e a relação que seus controladores mantêm entre si denunciam que ele é em quase tudo o avesso da estrutura de poder que vigorou na Primeira República.

O sistema político da Terceira República (1937-1945) era altamente institucionalizado, ou melhor, burocratizado, por oposição ao informalismo e aos acordos tácitos típicos da política dos governadores no pré-1930. Ele era 
unificado ideologicamente, ou ao menos se pretendia assim, e não vagamente "liberal". Esse sistema político não dependia do voto eleitoral para qualquer instância de governo, o contrário da regra de ouro da República Velha. E o fluxo de transmissão da legitimidade de um nível a outro não era ascendente (dos coronéis, que controlavam o eleitorado, ao presidente), mas descendente (da Presidência às prefeituras).

A hierarquia aqui entre municípios, estados e União, para falar na linguagem jurídica, é muito rígida, verticalizada e integrada e essa cadeia foi definida por uma série de disposições legais: prefeitos na base e presidente no topo estão ligados por uma carreira de aparelhos na qual um nível subordina-se política e burocraticamente ao outro. Ou melhor, onde "um nível serve-se de sua ascendência burocrática para governar politicamente o outro". Apenas a Interventoria e o Departamento Administrativo estão no mesmo nível, sutileza do legislador que não merece passar despercebida. Mais pelo desenho do que pelas práticas efetivas, o organograma sugere uma relação de supervisão recíproca, embora na realidade só o segundo tivesse, de fato, poder burocrático sobre a primeira (já que podia vetar suas decisões). A posição intermediária dos dois aparelhos divide o nível federal do nível municipal e essa simetria não é uma preferência estética, mas a maneira de superintender e controlar as iniciativas e as decisões mais desimportantes mesmo na ponta do sistema, propósito em tudo de acordo com a peculiar doutrina municipalista advogada pelo Estado Novo. O Ministério da Justiça e Negócios Interiores age, nessa geografia, como um filtro e como um dique, anteposto à Presidência. Ele atua executivamente através da Comissão de Estudos dos Negócios dos Estados, embora a função dessa Comissão, criada em 1939, devesse ser prestar "assistência técnica" ao Ministério "em todos os assuntos referentes à administração estadual que dependessem da aprovação do Presidente" (WAHrlich, 1983, p. 718) ${ }^{9}$. Por sua vez, o Departamento das Municipalidades, inventado já em 1938, age em nome do interventor e cumpre, diante dos prefeitos, praticamente a função que os departamentos administrativos desempenham no nível estadual diante do interventor: supervisão e controle. Submetido politicamente à Interventoria Federal, burocraticamente incumbido de processar os projetos anuais de orçamento elaborados pelas prefeituras e, caso desse tempo, formular sugestões técnicas para aperfeiçoar a administração municipal, os departamentos das municipalidades foram, na melhor das hipóteses, transformados num estágio obrigatório entre as prefeituras do interior e os departamentos administrativos por onde as decisões deveriam passar. E na pior delas convertidos tão somente em supercâmaras de vereadores. Segundo Mello, os departamentos das municipalidades acabaram por isso "dominados quase sempre por políticos de segunda ou terceira ordem" que terminavam por utilizar o aparelho "como instrumento dos seus interesses eleitorais" (MELLO, 1971, p. 69; apud Colussi, 1996, p. 92).

As associações políticas entre os controladores desses aparelhos seguiam, sempre a partir do topo do sistema, duas rotas. A primeira e mais comprida saía do presidente, pulava o ministro, chegava ao interventor, ao diretor do departamento das municipalidades e daí aos prefeitos. O primeiro nomeava o segundo e o terceiro e, esse último, o quarto e o quinto elementos ${ }^{10}$. A liberdade (e a discricionariedade) que o presidente usufruía na escolha dos interventores era semelhante à autonomia e arbitrariedade do interventor 
para indicar seus prefeitos. Todavia, a clientela de intendentes municipais não era similar à freguesia de interventores federais já que esses últimos sempre podiam acumular mais poder que aqueles e subir o valor das transações no mercado de apoios políticos.

A segunda rota saía também do presidente, passava, ao contrário da primeira, pelo ministro da Justiça e chegava enfim aos departamentos administrativos. Ainda que a nomeação legal dos seus ocupantes coubesse apenas ao chefe do Executivo federal, a recomendação de possíveis integrantes ou provinha do próprio ministro, ou passava por ele, já que seu titular filtrava candidatos apresentados pelas elites locais ou mancomunados com os interventores. Nesse contexto legal, os intervetores federais desejariam tudo, exceto um departamento politicamente antipático a suas propostas e iniciativas.

Em resumo: existe uma novidade aqui que permite ver onde e como se reproduz o sistema de dominação política e quem se encarrega, ao menos em parte, dessa reprodução. Insisto sobre esse ponto, mesmo correndo o risco de me repetir: é preciso levar em conta as instituições políticas do Estado Novo, ainda que elas façam toda figura de repartições "administrativas". E preciso levar em conta também a função burocrática dos seus controladores, ainda que se reconheça a centralidade e a importância do personalismo autoritário e do seu papel na construção e na estabilização do regime político autoritário. "Autoritarismo", nesse sistema, não é igual a personalismo. $\mathrm{O}$ personalismo é a forma de resolução dos conflitos nesse regime; as instituições autoritárias são, no caso, os meios.

Retomando o programa de pesquisa sugerido por Fausto (1972), pode-se verificar, com base no raciocínio e nas informações expostas neste artigo, que são as instituições políticas - essas instituições políticas, ou melhor: essa configuração institucional - as responsáveis, ou melhor, um dos dispositivos responsáveis para realizar, na prática, a capacidade estatal, ou 'a supremacia do Estado sobre a sociedade', conforme sua formulação. O Departamento

“A posição formal do Departamento, no sistema administrativo do Estado Novo, permite deduzir as relações estratégicas entre os diversos centros de poder, do nível federal ao municipal, e suas respectivas funções políticoburocráticas.”

Administrativo dos estados é uma forma particularmente útil para viabilizar o novo compromisso interelites. Esse compromisso é, por sua vez, a garantia da autonomia do Estado nacional diante das situações políticas regionais. Para compreender esse aspecto é suficiente afirmar que o ingresso da elite tradicional no aparelho do Estado, via daspinhos, aumenta, paradoxalmente, a independência desse Estado, já que os políticos têm pouco 
controle sobre o processo decisório, centralizado na Presidência da República, e baixa influência sobre o processo político como um todo, já que perderam para sempre dois de seus principais instrumentos de atuação: os partidos oligárquicos e o sistema eleitoral. A liberdade de ação da Presidência e dos "órgãos técnicos" a ela associados é, entre todos os indicadores desse período, o melhor índice para estimar o grau dessa autonomia.

Por isso, a função das instituições autoritárias e, em especial, a função do Departamento Administrativo foi, nesse contexto, certa: à medida que ele ampara e abriga as demandas dos oligarcas por presença e participação na "vida política", também serve de endereço para hospedar, tutelar e dar um formato mais moderno (isto é, "burocrático") à política nacional e ao espírito conservador da elite.

\section{Conclusões}

A explicação sobre a invenção de um aparelho como os departamentos administrativos envolve um risco evidente, ou seja, a tentação das explicações funcionalistas. Pensando esse caso de modo mais amplo, o problema fica mais enfático - e mais interessante - quando vem associado a uma questão teórica: como e por que instituições mudam ao longo do tempo?

Explanações usuais para essa charada tendem quase sempre a enfatizar obrigações sistêmicas: instituições são produzidas, transformadas ou mesmo desaparecem em razão das necessidades objetivas que cumprem. Assim, o procedimento mais simples (e mais arriscado) seria deduzir os motivos da criação do Departamento Administrativo das funções que ele cumpriu depois que foi criado. Essa posição tem o inconveniente de tomar o propósito inicial pela finalidade, que pode inclusive ter-se alterado ao longo do tempo graças à interação e aos confrontos com outras instituições, ou mesmo em função das alterações no meio ambiente político. Outra suposição igualmente problemática consiste em optar por explicar o desenvolvimento institucional por uma espécie de "partenogênese organizacional": uma instituição (no caso, o Departamento Administrativo) seria gerada da institucionalidade anterior (o regime de intervenção nos estados, por exemplo), como um efeito sem causa identificável.

Por outro lado, quando se assume uma perspectiva mais contextual que funcional, o que ressalta na explicação são justamente os confrontos políticos e burocráticos que deixam ver, nessas opções institucionais, decisões mais ou menos conscientes (escolhas entre alternativas, projetos, deliberações), e na definição final do desenho institucional do regime do Estado Novo o resultado da luta, até certo ponto bem explícita, entre as forças políticas em presença.

De toda forma, esse dispositivo administrativo, imaginado originalmente como uma forma de controle e não como um canal de representação dos setores descontentes da elite estadual, só na aparência pode ser percebido como resultado da infinita capacidade do presidente em "conciliar os opostos", conforme a mitologia varguista. Ele deve ser visto, na realidade, como um modo possível de ingresso da elite política - ou pelo menos de uma parte dela, a que havia restado depois de inúmeras composições, destituições, reabilitações e recomposições - na arena política. É certo que a configuração institucional depois de 1939 queria responder às pressões acumuladas (mas difusas) da oligarquia tradicional por 
participação política desde o Governo Provisório (1930-1934). No entanto, desde que isso fosse feito "administrativamente". O característico é que a fórmula adotada para a solução dos conflitos no universo das elites - e que tem no Departamento Administrativo uma espécie de "princípio lógico e fim prático" - se dá através de um aumento do controle da elite nacional sobre a elite regional. Esse é um dos fatos que está na base da inflação do poder do Estado brasileiro no pós-1930.

(Artigo recebido em outubro de 2011. Versão final em novembro de 2011).

\section{Notas}

${ }^{1}$ Esses conselhos foram instaurados em todos os estados do Brasil, em alguns municípios e no Distrito Federal pelo Decreto n ${ }^{\circ} 20.348$, de 29 de agosto de 1931. Eles funcionavam, ainda que sem muita capacidade decisória efetiva, como um complemento político ao poder do interventor após a Revolução de 1930. Ver o decreto do "Código dos Interventores" de 1931 em Carone, 1975, p. 374-381.

${ }^{2} \mathrm{O}$ presidente refere nessa passagem a gestão do interventor do Rio Grande do Sul para onerar "a União" com alguma obrigação adicional e a gestão do secretário de Viação de São Paulo, para desonerar o estado da taxa federal cobrada do Porto de Santos. Entrada do dia 28 set. 1938.

${ }^{3}$ Todas as passagens entre aspas são do Diário de Vargas. Para a data inicial de concepção do decreto-lei, ver a entrada de 16 jan. 1939; para a assinatura do documento, ver a entrada de 8 abr.; para a apreensão dos interventores, 14-16 abr.; para a atuação do governador de Minas Gerais contra o Código, ver a entrada de 19 maio; para a gestão do interventor do Rio Grande do Sul, 22 maio; e para a pressão de Osvaldo Aranha, ver a entrada de 9 jun. Cf. Vargas, 1995, vol. II, p. 192, 215, 217, 224, 224-225 e 230, respectivamente.

${ }^{4}$ Não consegui determinar a informação, mas parece que a denominação oficial do órgão era "Comissão de Revisão dos Projetos de Lei”, criada pelo Decreto-lei 1.019, em 31 dez. 1938. Ela era integrada pelo consultor-geral da República, pelos consultores jurídicos do Ministério do Trabalho e da Justiça e pelo ministro dessa pasta.

${ }^{5}$ Bilhete manuscrito de Maciel Filho a Getúlio Vargas. Museu da República. Arquivo Histórico. Arquivo Getulio Vargas - GV cr 940.00.00 GV 04 cr (1).

${ }^{6}$ Bilhete manuscrito de Maciel Filho a Getúlio Vargas, cit.

${ }^{7}$ Arquivo Nacional. Fundo: Gabinete Civil da Presidência da República. Série: Governos Estaduais. Lata 268. Documento no 4927.

${ }^{8}$ Trata-se de trecho de uma carta enviada de Paris em 25 fev. 1939.

${ }^{9}$ A comissão era integrada por onze pessoas, entre os quais o presidente do Dasp. Como mais tarde esclareceu o ministro Marcondes Filho, a Comissão era, na "órbita federal", "o aparelho destinado a divulgar igualdades desconhecidas e a aplainar diferenças evitáveis" resultantes dos processos decisórios dos departamentos administrativos. Discurso proferido pelo ministro Marcondes Filho, O Estado de S. Paulo, 11 nov. 1943, p. 6.

10 Benedito Valadares gaba-se de ter sido o autor da "emenda" à Constituição de 1937, que deu o poder de nomeação dos prefeitos ao interventor (artigo 27). Segundo ele, "era um dispositivo esdrúxulo, mas necessário" (VALADARES, 1966, p. 164). 


\section{Referências bibliográficas}

Andrade, Almir de. O Brasil e a centralização do governo (Editorial). Cultura Política, Rio de Janeiro, n. 4, jun. 1941.

Campos, Francisco. O Estado nacional: sua estrutura; seu conteúdo ideológico. Rio de Janeiro: José Olympio, 1940.

Carone, Edgard. A Segunda República (1930-1937). 3a. ed. São Paulo: Difel, 1978. . A Terceira República (1937-1945). $2^{\text {a }}$ ed. São Paulo: Difel, 1982. . O Estado Novo (1937-1945). 1ª reimpr. Rio de Janeiro; São Paulo: Difel,

1977.

. O tenentismo: acontecimentos; personagens; programas. São Paulo: Difel,

1975.

Codato, Adriano. Elites e instituições no Brasil: uma análise contextual do Estado Novo. Tese (Doutorado em Ciência Política). Departamento de Ciência Política. Instituto de Filosofia e Ciências Humanas. Universidade Estadual de Campinas (UniCAmP), 2008.

Colussi, Eliane L. Estado Novo e municipalismo gaúcho. Passo Fundo: Universidade de Passo Fundo, 1996.

CunHa, Wagner V. da. O sistema administrativo brasileiro (1930-1950). Rio de Janeiro: Instituto Nacional de Estudos Pedagógicos, 1963.

Diniz, Eli. O Estado Novo: estrutura de poder; relações de classes. In: FAusto, Boris (org.), História geral da civilização brasileira. Tomo III: O Brasil Republicano, $3^{\circ}$. Vol. Sociedade e Política (1930-1964). 5ª ed. Rio de Janeiro: Bertrand Brasil, 1991.

Fausto, Boris. Pequenos ensaios da história da República: 1889-1945. Cadernos CEBRAP, São Paulo, n. 10, 1972.

FGv-Cpdoc. Era Vargas $1^{\circ}$ Tempo: dos anos 20 a 1945. CD-rom, 1996.

Hayashi, Marli G. A gênese do ademarismo (1938-1941). Dissertação (Mestrado em História Social). Universidade de São Paulo. São Paulo (SP), 1996.

Ianni, Octavio. Estado e planejamento econômico no Brasil (1930-1970). Rio de Janeiro: Civilização Brasileira, 1971.

Krasner, Stephen D. Approaches to the State: Alternative Conceptions and Historical Dynamics. Comparative Politics, vol. 16, n. 2, p. 226-246, Jan. 1984.

LEAL, Victor Nunes. Coronelismo, enxada e voto: o município e o regime representativo no Brasil. 2a ed. São Paulo : Alfa-Omega, 1975.

LinZ, Juan J. Regimes autoritários. In: PinheIro, Paulo S. (coord.). O Estado autoritário e os movimentos populares. Rio de Janeiro: Paz e Terra, 1980.

Loewenstein, Karl. Brazil under Vargas. New York: The Macmillan Company, 1944.

Martins, Luciano. Estado Novo. FGV-CPDOC. Dicionário histórico-biográfico brasileiro (19301983). Rio de Janeiro: Forense-Universitária/Finep, 1983.

Mello, Diogo Lordello de. O município na organização nacional. Rio de Janeiro: IBAM, 1971. 
Oliveira, Armando de Salles. Escritos políticos. São Paulo: Arx, 2002.

Pontes de Miranda, Francisco Cavalcanti. Comentários à Constituição Federal de 10 de Novembro de 1937. Rio de Janeiro: Irmãos Pongetti Editores, 1938.

Rodriguez, Ricardo Vélez (org.), Cultura Política e o pensamento autoritário. Brasília: Câmara dos Deputados. Centro de Documentação e Informação. Coordenação de Publicações, 1983.

SolA, Lourdes. O golpe de 37 e o Estado Novo. In: MOTA, Carlos G. (org.). Brasil em perspectiva. 19a ed. Rio de Janeiro: Bertrand Brasil, 1990.

Souza, Maria do C. C. Estado e partidos políticos no Brasil (1930-1964). 3ª ed. São Paulo: Alfa-Omega, 1990.

Valadares, Benedito. Tempos idos e vividos. memórias. Rio de Janeiro: Civilização Brasileira, 1966.

VARGAS, Getúlio. A atualidade brasileira e a solução dos seus problemas. In: . $A$

nova política do Brasil. Rio de Janeiro: José Olympio, 1940, vol. VII: No limiar de uma nova era.

Vargas, Getulio. Getúlio Vargas: diário. São Paulo: Siciliano; Rio de Janeiro: Fundação Getúlio Vargas, 1995.

WahrLich, Beatriz M. de S. Reforma administrativa na era de Vargas. Rio de Janeiro: Ed. da Fundação Getúlio Vargas, 1983.

\section{Documentos históricos}

Arquivo Nacional. Fundo: Gabinete Civil da Presidência da República. Série: Governos Estaduais. Lata 268. Documento no 4.927.

Museu da República. Arquivo Histórico. Arquivo Getulio Vargas - GV cr 940.00.00 GV 04 cr (1).

\section{Artigos de jornais}

Marcondes Filho, Alexandre. "Discurso proferido pelo ministro Marcondes Filho". O Estado de S. Paulo, 11 nov. 1943. 


\section{Resumo - Resumen - Abstract}

Intervenção estatal, centralização política e reforma burocrática: o significado dos Departamentos Administrativos no Estado Novo

Adriano Codato

O objetivo deste artigo é expor e explicar um momento específico da evolução políticoinstitucional brasileira. São explorados os conflitos que estão na origem da escolha e a implementação de uma nova ordem político-administrativa no pós-1930. São examinadas as origens, a concepção e os objetivos que guiaram a invenção de um aparelho burocrático que, juntamente com o interventor federal, não só controlou as elites políticas regionais, mas também contribuiu para a organização do poder do Estado em bases nacionais, cooperando para viabilizar a capacidade estatal: os Departamentos Administrativos. Analiso o contexto político, os antecedentes legais e as inovações institucionais do decreto-lei n ${ }^{\circ} 1202 / 39$, a fim de responder a duas questões bem específicas: por que e com que objetivo essa lei sobre a administração dos estados e dos municípios foi criada durante o Estado Novo?

Palavras-chave: Departamento Administrativo; Governo Vargas; administração pública.

La intervención del Estado, la centralización política y la reforma burocrática: el significado de los Departamentos Administrativos en el Estado Novo Adriano Codato

El objetivo de este trabajo es exponer y explicar un punto específico de la evolución de la política brasileña institucional. Se exploran los conflictos que llevaron a la elección y aplicación de un nuevo sistema político-administrativo en el post-1930. El documento explora los orígenes, el diseño y los objetivos que llevaron a la invención de un aparato burocrático que, junto con el interventor federal, no solamente controla las élites políticas regionales, sino que también contribuyó a la organización del poder estatal a nivel nacional, cooperando para facilitar la capacidad del Estado: los Departamentos Administrativos. Analizo la historia política, jurídica y las innovaciones institucionales del Decreto-Ley 1202/39, con el fin de responder a dos preguntas muy concretas: por qué y para qué esta ley sobre la administración de gobierno estatal y local se creó durante el Estado Novo.

Palabras clave: Departamento Administrativo; Gobierno Vargas, administración pública.

State intervention, political centralization and bureaucratic reform: the meaning of the Administrative Departments in Estado Novo

Adriano Codato

The purpose of this paper is to expose and explain a precise moment of the Brazilian political-institutional evolution. It explores the conflicts that are at the origin of choice and implementation of a new politico-administrative system in post-1930. The paper explores the origins, design and objectives that drove the invention of a bureaucratic apparatus which, together with the Federal Interventor, not only controls the regional political elites, but also contributed to the organization of state power on a national basis, cooperating to facilitate state capacity: the Administrative Department. I analyze the political context, legal history and the institutional innovations of the Decree-Law 1202/39 in order to answer two very specific questions: why 
and for what purpose this law on the administration of state and local government was created during the Estado Novo.

Keywords: Administrative Department, Vargas government, public administration.

\section{Adriano Codato}

Doutor em Ciência Política pela Universidade Estadual de Campinas (Unicamp). É professor de Ciência Política na Universidade Federal do Paraná (UFPR), editor da Revista de Sociologia e Política e um dos coordenadores do Núcleo de Pesquisa em Sociologia Política Brasileira (NUSP) da UFPR. Contato: adriano@ufpr.br 


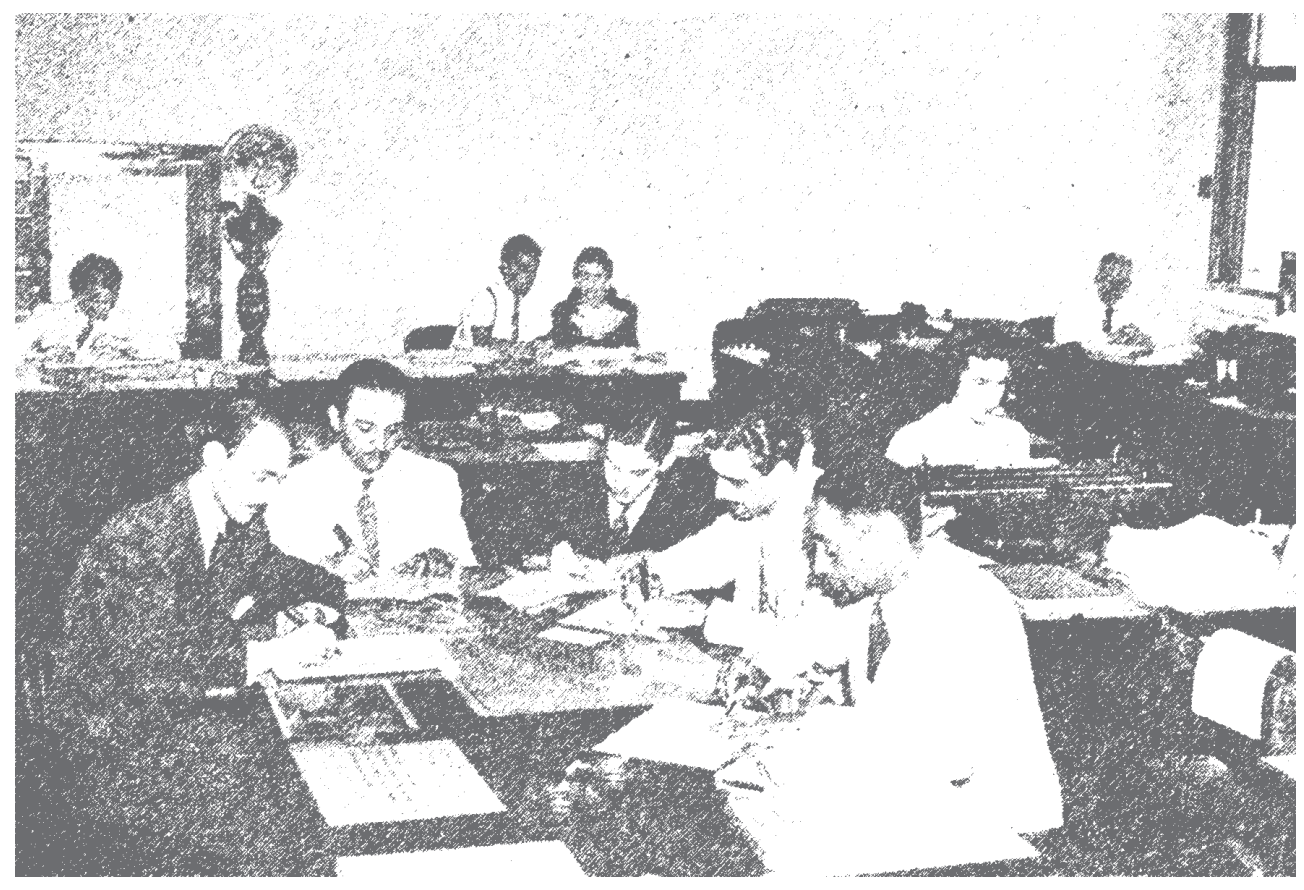

